\title{
A Pragmatist and Feminist Relational (E)pistemology
}

\section{Barbara Thayer-Bacon}

\section{(2) OpenEdition}

\section{Journals}

\section{Electronic version}

URL: http://journals.openedition.org/ejpap/948

DOI: $10.4000 /$ ejpap.948

ISSN: 2036-4091

\section{Publisher}

Associazione Pragma

\section{Electronic reference}

Barbara Thayer-Bacon, «A Pragmatist and Feminist Relational (E)pistemology », European Journal of Pragmatism and American Philosophy [Online], II-1 | 2010, Online since 01 July 2010, connection on 20 April 2019. URL : http://journals.openedition.org/ejpap/948 ; DOI : 10.4000/ejpap.948

This text was automatically generated on 20 April 2019.

\section{(c) $\Theta \Theta \Theta$}

Author retains copyright and grants the European Journal of Pragmatism and American Philosophy right of first publication with the work simultaneously licensed under a Creative Commons AttributionNonCommercial-NoDerivatives 4.0 International License. 


\title{
A Pragmatist and Feminist Relational (E)pistemology
}

\author{
Barbara Thayer-Bacon
}

\section{AUTHOR'S NOTE}

This essay is derived from the Introduction and Chapters One, Two, and Three of my (2003) Relational “(e)pistemologies."

\section{Introduction}

1 In 1966 two sociologists, Peter L. Berger and Thomas Luckmann, published a small yet influential book, titled The Social Construction of Reality, in which they argue that reality is socially constructed and that it is the task of the sociology of knowledge to analyze the process in which this occurs (1966: 1). They acknowledge in their Introduction that "reality" and "knowledge" are two terms with a long philosophical history, and they are careful to claim they are not using the terms in a philosophical way, but rather within the context of sociology. Berger and Luckmann describe the task of the philosopher as one of trying to differentiate between valid and invalid assertions about the world, in a general sense, whereas sociology of knowledge is concerned with reality and knowledge within the context of various social settings. The sociologist must keep quotation marks around the terms reality and knowledge.

Berger and Luckmann (1966) assume epistemology is a study of knowledge without quotation marks, Knowledge that is really true, whereas the sociology of knowledge studies common people's claims to "knowledge" that are assumed beliefs, maybe even justified beliefs, but not necessarily true. Epistemologists establish the criteria and standards necessary to prove validity and truth. As epistemology traditionally has defined knowledge, only what we believe is true, have good reason to believe is true, and in fact is true, can we call knowledge. Knowledge $=$ Truth. Because knowledge is defined 
as what is justified true belief, then it is necessary for sociologists to qualify their studies because they are not claiming that what common people believe is "true" is really true. They are not claiming that what people believe is "real" really is. Their task is to study how beliefs come to be viewed as real and true. Philosophers, according to the tradition which Berger and Luckmann reflect rather than question, have the task of proving the validity of truth claims, of making the case for warranted assertions that are justified as necessarily so.

3 I question that it is possible to accomplish what transcendental epistemologists claim to be able to do. I want to suggest that we can never remove the quotation marks from around knowledge and reality. I join others in arguing that none of us have access to transcendence, none of us can know what is True or Real, in a universal sense, and so we must all be content to continue to talk about "knowledge" and "reality" as Berger and Luckmann do, with quotation marks around the terms. Like Berger and Luckmann, I want the reader to know up front that I symbolically place quotation marks around the concept "epistemology" to distinguish it from the philosophical definition of epistemology as transcendental, even though I will not literally place " " around the term each time I use it, for ease of reading. I will follow Richard Rorty's (1979) lead and capitalize Epistemology when I use the term in the traditional philosophical sense, with an assumption of absolutism. However, I am not just striving to use the term 'epistemology' in a traditional sociological way here either. I want to redefine epistemology. I want to reconstruct the meaning of the term. I will adopt a methodological tool often used in postmodern discourse and place parenthesis's around the $e$ of epistemology, like so, (e)pistemology, to further remind the reader when I am using the term epistemology in a non-transcendent way, meaning within the context of this world, not removed from our ordinary, everyday experiences.

4 Like Dewey, I argue that "the most pervasive fallacy of philosophic thinking goes back to neglect of context, to philosophy's effort to describe itself in a transcendental manner, removed from the context of the everyday, common world" (Dewey, 1960: 92). I question philosophy's assumed ability to tell us what is a priori Truth and Goodness and Beauty, as well as science's assumed ability to avoid philosophical questions. I join feminists and postmodernists in reasserting the need to uncover the philosopher's assumption of power. Along with other pragmatists, I agree that the philosopher's role should be one of cultural critic, and helping to develop ideas to deal with the actual crises of our lives. Philosophers can help to guide historical change intelligently because not only do they legitimate conformities, they also question conformities that have become so habitual that they are taken to be Reality or Truth. I do not intend to offer an extensive argument for the demise of Epistemology in this essay, Richard Rorty (1979) has already done that very well, as did John Dewey (1938) before him, with his Logic. There are many others who have contributed to the death of transcendental Philosophy, and Epistemology in particular, as well.

5 My task is to describe a non-transcendent (e)pistemology. My voice is one that is attempting to contribute to the demise of traditional Epistemology, while at the same time reclaiming traditional Epistemological concerns of standards and criteria for warranting arguments and determining truths from falsities. These concerns must be reclaimed in order to make them visible and hold them accountable as well as make them pragmatically useful, but on socially constructed grounds, not on transcendental grounds. We must confront Epistemology, and deconstruct it, so that we can dissolve the 
dualisms it creates and move on. These dualisms include for example: absolute/relative, subjective/objective, mind/body, knower/known.

What I offer here is one pragmatist social feminist view, a relational perspective of knowing. I seek to offer an epistemological theory that insists that knowers/subjects are fallible, that our criteria are corrigible, and that our standards are socially constructed, and thus continually in need of critique and reconstruction. I offer a self-conscious and reflective epistemological theory, one that attempts to be adjustable and adaptable as people gain further in their understanding. This epistemology must be inclusive and open to others, because of its assumption of fallible knowers. And, this epistemology must be capable of being corrected because of its assumption that our criteria and standards are of this world, one's we, as fallible knowers socially construct.

7 'Relations' form the heart of this (e)pistemological theory and are a unique contribution I have to offer, in terms of drawing our attention to relational forms of knowing as opposed to individual descriptions, which have dominated Euro-western Epistemological theories for so long. I certainly do not want to claim to have discovered relational approaches to knowledge. In fact, to make such a claim contradicts my own theory. I argue that we become knowers and are able to contribute to the constructing of knowledge due to the relationships we have with others. None of us are able to make contributions without the help of others, and none of us discover new ideas all on our own. I describe a theory of knowing that aims to show how interconnected we all are, not just to each other personally, but also to our social environments, our cultures, past, present, and future, as well as our surrounding natural environment, and the forces of the universe as a whole. I also describe how much our individual, unique ideas are caught up within webs of related ideas.

8 My relational epistemology calls for active engagement, aims at democratic inclusion, joins theory with praxis, strives for awareness of context and values, while tolerating vagueness and ambiguities. I argue that knowing is something people develop as they have experiences with each other and the world around them. People improve upon the ideas that have been socially constructed and passed down to them by others. They do this improving by further developing their understandings and enlarging their perspectives. With enlarged perspectives people are able to create new meanings for their experiences. In summation: My relational epistemology views knowing as something that is socially constructed by embedded, embodied people who are in relation with each other.

9 My plan is to present the feminist and pragmatist sides of this debate sequentially in sections one and two, ${ }^{1}$ turning to Lorraine Code's concern for a "responsibilist" epistemology and Sandra Hardings' feminist standpoint as well as Charlene Haddock Seigfried's call for feminists to give up the epistemological project from the feminist side of the debate. John Dewey's work will take center stage in the discussion of pragmatism's side of the debate. I will end this discussion by co-opting (e)pistemology and removing its absolute status, even in its non-vulgar form, in exchange for a qualified relativist status. I will reclaim the value and importance of being able to make judgments and present our arguments based on criteria that are socially constructed and therefore open to criticism and improvement. I will keep in check (e)pistemology's will to transcendental power and its desire to embrace dualisms such as knower/known, mind/body, theory/practice, subject/object. Thus, the reader should end these sections with a good sense of my position within the epistemological debate, as well as a better understanding of why I continue to use the word epistemology, though in its altered form of (e)pistemology. 


\section{Some Feminist Concerns} based on logical reasoning rather than empirical methods, which are science's realm. Philosophers analyze and critique "fundamental beliefs," and they investigate causes and laws "underlying reality." Here, we find that we must capitalize Philosophy right from its beginning because the assumption of universality is built right into its definition. Inquiry into the nature of things, into fundamental beliefs, and underlying reality, is inquiry in a universal, general way, divorced from its particularity.

In Feminist Epistemologies, Linda Alcoff and Elizabeth Potter (1993) note in their introductory essay that feminists began contributing to Philosophy from the margins, and they have moved to the center. The margins are the applied fields, in particular applied ethics, which is where feminist work was first published. "Feminist philosophers began work in the applied areas because feminism is, first and last, a political movement concerned with practical issues, and feminist philosophers understood their intellectual work to be a contribution to the public debate on crucial practical issues" (such as the right to equal job opportunities, and to own property) (Alcoff \& Potter 1993: 2). The center, or what Alcoff and Potter call "the 'core' areas" of Philosophy are Epistemology and Metaphysics.

Alcoff and Potter (1993) inform us that when feminists began working in the field of Epistemology, their contribution was as critique of the tradition, as was their contribution in the other philosophical fields of study. If Epistemology is defined as a theory of knowledge in general, then a feminist epistemology that refers to women's experiences, is an oxymoron, due to its efforts to focus on the particularity of women instead of the generality of human beings. And, indeed, when feminists began contributing to Epistemology they were criticized for not doing Epistemology, as it has been historically defined. Feminists found that they can only begin to contribute to Epistemology by first challenging the Philosophical premise "that a general account of knowledge, one that uncovers justificatory standards a priori, is possible" (Alcoff \& Potter 1993: 1; emphasis in original). Feminists argue that while 'human beings' is a concept that claims to include "all people," it really has historically been an androcentric concept that represents a male perspective. Since traditional Epistemology has not been able to present a generality but rather has represented a male perspective as if it is general, neutral, and inclusive of women, then there is the possibility of offering a feminist epistemology. This is why critique of the tradition has to come first, in order to create a space where feminists can begin to actually do constructive and reconstructive work in (e)pistemology. Many feminists have contributed to the argument that girl/woman is excluded from the concept "human beings" ("mankind") and treated as "other" in Eurowestern philosophy. ${ }^{2}$ Once establishing that the female voice has been excluded from Philosophy in general, which I think most philosophers would agree has been successfully accomplished, the next step is to establish the exclusion of the female voice within the field of Epistemology.

13 A significant example of androcentrism in Philosophy is demonstrated by the association of Philosophy with the mind, which is linked to males, in contrast to the body, which is connected to females. Although Descartes usually gets blamed for splitting the mind from the body in Euro-western philosophy (Bordo 1987; Rorty 1979), I argue that we can go 
back to ancient Greece and find many examples of Plato severing the mind from the body, and assigning the body to a lesser status (Thayer-Bacon 2000). A most vivid example of Plato's separation and assigned value can be found in his theory of knowledge. Plato describes each of us as having an immortal soul that knows all, and we forget what we know when our souls inhabit our bodies at birth. Thus, our bodies cause us to forget all knowledge, and we are doomed to spending our lifetimes trying to remember what we already knew.

Once the body is split from the mind, and given a lesser status as that which serves as a barrier, deceives us, and lures us away from seeking Truth due to its earthly passions, then it is an easy next step to associate women with the body. Simone de Beauvoir (1952/89) carefully makes the argument that there are only two things that distinguish women from men when we look at cultures around the world and through-out time, and yet these two things have been used to assign women an inferior, Other, status in many cultures. Given the inferior status of the body, it is not surprising to find that these two things that distinguish women from men have to do with women's physical bodies, that they have weaker muscles and they menstruate. de Beauvoir points toward the future when technology will help women compensate for their weaker muscles, and birth control will bring their reproductive systems within their control. When that day comes, de Beauvoir predicted that women may finally be given an equal status. That day that de Beauvoir predicted is here for many women, still women have not yet reached an equal status. Neutralizing bodily differences is not enough to change women's status; the status of the body must be raised and it must be reconnected to the mind. Feminists realize now that in order to help put an end to the androcentrism in Philosophy, we must call into question the body/mind split, and make the case for a wholistic bodymind. That argument comes from many diverse camps, and is presented in my (2003) larger text in chapters on personal relations, w/holistic relations, ecological relations, and scientific relations.

Traditional Epistemology shows its androcentricism with its embrace of Rationality as an Ideal, for rationality (or reason) is again associated with the mind, which is linked to males. Irrationality, in contrast, is associated with the emotions and intuitions, which are normally attributed to women. So, historically within the field of Epistemology, males function as the model for rationality and females serve as the model for irrationality. Feminists have argued for the value of intuition and emotions (and imagination) in reason, by turning to women's experiences and describing women's ways of knowing (Belenky et al. 1986; Gilligan 1982; Martin 1994; Ruddick 1989). Along with traditional androcentric Epistemological models, we now have examples of gynocentric (female) Epistemological models (Duran 1991). However, claiming a distinctive status for women as knowers not only serves to raise their status, it also continues to maintain a gender split. As long as a gender split is maintained, women still serve in the role of Other defined in contrast to rational males. Once again, feminists have learned that the best way to gain women's status as rational beings who are potential knowers is to call into question the rational/irrational (mind/body) split, and to show that all of us use many tools to help us construct knowledge, our reason, emotions, intuition, and imagination, for example (Thayer-Bacon 2000).

16 Another good place to look for androcentrism in Epistemology is with the "subject," ' $S$ ' in "S knows that $\mathrm{p}$ " statements. The subject, the knower, the epistemic agent, are all quite objective, neutral terms that could represent anyone, so it seems. In fact, not only is the knower represented with neutral terminology, the importance and weight of considering 
'S's' contribution to 'that $\mathrm{p}$ ' is minimalized, thus devaluing the importance of ' $\mathrm{S}$ ' even more. Historically, Epistemology has been based on an assumption that subjects (S) do not need to be taken into consideration in determining 'that p.' As Epistemology has historically developed, the subject, $\mathrm{S}$, has been severed from 'that $\mathrm{p}$ ' and the attention of epistemologists has been focused on 'that p,' at the expense of 'S.' Euro-western Philosophy concerns itself with the product of knowers' efforts. Knowers are separated from what is known, and devalued in importance.

17 Lorraine Code (1987) argues that not taking subjects into account leads us to the following traditional Epistemological conclusions:

(1) that knowledge properly so-called is autonomous in that it is of no epistemological significance whose it is; (2) that knowledge acquisition may be of psychological interest but it is irrelevant to an epistemologist's quest for criteria of justification, validity, and verification; and (3) that knowledge is objective in the sense that discussion of the character and epistemic circumstances of subjects has nothing to contribute to the proper epistemological task of assessing the product. (Code 1987: 25-6)

If we can ignore knowers in our quest for knowledge, then we can ignore questions such as how do we come to be knowledgable, and for what purpose is such knowledge? We can ignore questions that draw our attention to the context of knowing, show the connection of knowledge with values, and point to issues of power. We can ignore gender, class, ethnicity, and race as categories of concern, for example. If we diminish the importance of subjects, then we can pretend to offer a neutral, general theory of knowledge, when what we really offer is an androcentric Epistemology. The androcentrism is visible in the objectification and neutralization of the subject.

Lorraine Code's work has contributed to a feminist effort to bring the subject, 'S,' more directly into discussions of epistemology. In Epistemic Responsibility her (1987) focus is on making the case that there are moral implications to knowledge claims, and that we need to understand how directly connected morality is to epistemology. Code's central claim is "that knowing well is as much a moral as it is an epistemological matter" (Code 1987: 252). The way we understand that knowing well is a matter of considerable moral significance is to pay attention to the character of would-be knowers. Code tells us she is trying to shift the emphasis of investigation and evaluation so that knowers come to bear as much of the onus of credibility as "the known" (Code 1987: 8-9). She wants to put "epistemic responsibility" in a central place in theories of knowledge. ${ }^{3}$ She wants to insist that knowers must be held accountable to their community as well as to the evidence.

In "Taking Subjectivity into Account," Code (1993) again takes up the topic of looking at ' $S$ ' of ' $\mathrm{S}$ knows that $\mathrm{p}$ ' statements. Here she makes the case these statements are representative of a "received" knowledge model that is very narrow and limited in scoop. By "received" knowledge, she means "conditions that hold for any knower, regardless of her or his identity, interests, and circumstances (i.e., her or his subjectivity)" (Code 1993: 15). This dominant Enlightenment Epistemological theory, see for example Harvey Siegel (1987, 1997), relies on Ideals of objectivity and value neutrality (Siegel's non-vulgar absolute), to argue that Reason allows ' $\mathrm{S}$ ' to transcend particularity and contingency. Thus ' $\mathrm{S}$ ' is suppose to represent anyone and everyone (no one in particular). Code wants to seriously entertain a model of "constructed" knowledge, that "requires epistemologists to pay as much attention to the nature and situation - the location - of $S$ as they commonly pay to the content of $p ;$ [...] [she maintains] that a constructivist reorientation requires epistemologists to take subjective factors - factors that pertain to the 
circumstances of the subject, $S$ - centrally into account in evaluative and justificatory procedures" (Code 1993: 20). ${ }^{4}$ Thus, gender, race, class, ethinicity become recognized as primary analytic categories as we move to take subjectivity into account.

Code (1993) makes the case that subjectivity is always there, hidden, despite disclai- mers, and that we can always find the context that is being suppressed. Subjectivity is found in the examples selected for discussion, and the experiences used to represent "human thought," for example. Contra to traditional Epistemologists, Code argues that "taking subjectivity into account does not entail abandoning objectivity" (Code 1993: 36; emphasis in original). What it does is help us guard against reductivism and rigidity. It allows us to accommodate change, by letting knowledge claims be provisional and approximate. Code describes herself as a "mitigated relativist," who argues that epistemology has no ultimate foundation, "but neither does it float free, because it is grounded in experiences and practices, in the efficacy of dialogic negotiation and of action" (Code 1993: 39). This is similar to my qualified relativist position which I $(2002,2003)$ further develop in Relational “(e)pistemologies," Chapter Two.

What we have found out so far in this section is that feminists have successfully made the case for Philosophy's androcentrism, as well as Epistemology's androcentrism. Feminists have argued soundly for the dissolving of the body/mind dualism and for taking subjectivity into account as they make the case for viewing knowledge in relation to knowers. Current male philosophers, such as Siegel $(1987,1997)$ are careful not to claim a spectator's view of knowledge, and are willing to acknowledge their own embeddedness. Yet they do not want to relinquish the claim to epistemic privilege that they have held for so long, for fear they will be left with nothing (relativism). In their efforts to hold back subjectivity and contextuality so that they admit some, but not so much that all is lost, some traditional Epistemologists such as Siegel have found allies amongst feminists, in particular spontaneous empiricist feminists and standpoint feminists, as labeled by Sandra Harding $(1991,1993)$. Like her, these feminists tend to work in various fields of science.

According to Harding (1993), spontaneous empiricist feminists, such as Lynn Hankinson Nelson, Elizabeth Potter, and Helen Longino, argue that insufficient care and rigor in following the existing methods and norms is what has caused sexist and androcentric results in research. They do not think the problem lies in the basic canons, but rather with how we do science and philosophy. They recommend that what we need is more precision and clarity, what we need is to do good science and philosophy that is more careful and rigorous. Like Siegel $(1987,1997)$ in regards to Philosophy, empiricist feminists accept the inescapablity of social influence on the content of science. Longino's $(1990,1993)$ work helps us understand the deep hostility science and philosophy have historically expressed toward women. Elizabeth Potter (1993) and Lynn Nelson (1990, 1993) shed light on the negotiating process that goes on in science, within epistemological communities.

Nelson, Potter, and Longino each argue for a community's approach for establishing warrantability, as a way to undermine Epistemology's traditional transcendental perspective, as well as to avoid not being able to offer critique at all. Rather than thinking individuals are epistemic agents, that ' $\mathrm{S}$ ' is a single knower, they recommend we think of communities as the primary epistemic agencies. Code $(1987,1993)$ recommends this as well. This strategy to combat science and philosophy's hostility, Longino describes as "multiplying the subjects," or as "views from many wheres" (Longino 1993: 113; emphasis 
in original). If we treat science (and philosophy) as a practice, that commits us to viewing inquiry as ongoing and theories as partial, then "we can recognize pluralism in the community as one of the conditions for the continued development of scientific knowledge in this sense" (Longino 1993: 116). Longino concludes no segment of the community can claim epistemic privilege. She recommends the creation of what she calls a "cognitive democracy," of "democratic science," using public and common standards (Longino 1993: 118).

Harding, however, thinks "the methods and norms in the disciplines are too weak to permit researchers systematically to identify and eliminate from the results of research those social values, interests, and agendas that are shared by the entire scientific community or virtually all of it" (Harding 1993: 52, emphasis in original). The scientific method cannot rid itself of bias. Thus she recommends her strong objectivity method, which places the subjects of knowledge on the same critical, causal plane as objects of knowledge. Harding's "strong objectivity" requires that scientists (and philosophers) and their communities (Subjects) be critiqued as well as 'that p' (Harding 1993: 69).

All of the kinds of objectivity-maximizing procedures focused on the nature and/or social relations that are the object result of observation and reflection must also be focused on the observers and reflectors - scientists and the larger society whose assumptions they share. But a maximally critical study of scientists [philosophers] and their communities can be done only from the perspective of those whose lives have been marginalized by such communities. (Harding, 1993: 69)

Harding's strong objectivity method is based on a feminist standpoint epistemological theory. Harding and others, ${ }^{5}$ have made important points about who gets left out of communities of inquirers. They argue for the need to expand epistemological communities to include those on the margins, those outsiders who are not traditionally viewed as experts, such as women, people of color, and people lacking in property. Using Marx, Engels, and Lukacs (and Hegel) as their sources initially, feminist standpoint theorists seek to understand the relations between power and knowledge, by looking at collective subjects, groups with shared histories and shared locations in relation to power. They try to generate different accounts from the dominant ones and explore the intersections of different outsider perspectives (e.g. feminists of color, gay and lesbian accounts, etc.). They do not claim to have a traditional Epistemological goal of seeking Truth, rather their project is to understand power relations, in order to be able to change them, by privileging the speech of marginalized subjects. Their Subject focus is also not of individuals, but collective subjects, groups who share histories, experiences, based on their shared positionality in relations of power.

Feminist standpoint epistemologists adopt the traditional Epistemologist's claim to epistemic privilege by claiming epistemic privilege for those traditionally excluded from mainstream philosophy. According to Harding, their claim is "that all knowledge attempts are socially situated and that some of these objective social locations are better than others as starting points for knowledge projects [to] challenge some of the most fundamental assumptions of the scientific [and Philosophical] world view [...]" (Harding 1993: 56). Looking from the margins helps us see the dominant culture and its assumptions of superiority. Marginalized lives provide us with the problems and agendas for standpoint theories, but not the solutions. Feminist standpoint theory starts from women's lives, but these women are embodied and visible, and they are multiple and heterogenous, contradictary or incoherent. These marginal views are not just from our 
own marginalized lives, as women, but from other, different, and often oppositional women's lives as well (Harding 1993: 58).

Harding describes standpoint epistemologists as "sociological relativists" - but not epistemological relativists (Harding 1993: 61). Standpoint epistemologists want to have it both ways, they accept "the idea of real knowledge that is socially situated" (Harding 1993: 50). While Harding does not want to claim she has a God's eye view of what is Right/ True, she does want to claim the possibility of epistemic privilege, just with different subjects. She shifts the claim of critical leverage from the center to the margin, from philosophers and scientists, to those excluded from philosophy and science's androcentric theories. By doing so, she continues to use an absolutist tool (epistemic privilege) to try to dismantle absolutist Epistemology, in effect using a master's tool to try to dismantle the master's house (Bar On 1993). ${ }^{6}$ Another absolutist tool Harding insists on maintaining is "objectivity," even though she is well aware of how objectivity has been used in scientific projects that are now judged to be sexist, racist, classist, homophobic, etc. Harding argues " $(\mathrm{t})$ he notion of objectivity is useful in providing a way to think about the gap that should exist between how any individual or group wants the world to be and how in fact it is" (Harding 1993: 72). Thus we find she reveals her realist leanings. Longino (1993) describes Harding's standpoint theory as using the strategy of "changing the subject" to combat science and philosophy's hostility to girls/women, and she suggests Harding's standpoint theory begs the question.

Harding (1993) tries to deny that her project is an epistemological one, arguing instead that she is looking at political and social concerns. However, this sharp separation between epistemology and social and political theory undermines her own claim that "the grounds for knowledge are fully saturated with history and social life rather than abstracted from it" (Harding 1993: 57). What Harding needs to deny is that her project is a transcendental Epistemological one. She, and other feminists, make a significant contribution to the collapse of absolutist Epistemology by highlighting the relationship between knowledge and power. By showing transcendental Epistemology's biases and limitations, Harding contributes to the description of a transformed (e)pistemology on socially constructed grounds. If Harding's theory is an accurate description of knowing, then she cannot avoid using (e)pistemological theory in her own project. What she can do is avoid transcendental Epistemology, and the use of its tools (such as epistemic privilege and objectivity).

I agree with empiricist feminists and standpoint feminists that there is a need to embrace pluralism, and in fact I argue elsewhere that (e)pistemological fallibilism entails (e)pistemological pluralism, contra to Peirce and Siegel (Thayer-Bacon 2003: Chapter 2). However, I do not think any of us, as knowers, can escape our own social embeddedness completely, and therefore I do not think any one standpoint has the chance of offering us a privileged, clearer, sounder view. There are as strong of limitations on women's ways of knowing, as on men's, on Black's as on White's, on lower-classes' as on middle or upperclasses', on homosexual's as on heterosexual's ways of knowing, just to name a few categories. The argument for standpoint epistemology risks sliding into determinism on one end of the spectrum and reaffirming a spectator's view on the other end. I argue that where we fall is somewhere in-between. We are greatly determined by our social setting, as social beings, but we are also able to become aware of our embeddedness, because we are social beings. Others shape our views but others also help us become aware of how views differ. I do not want to argue that any of us has a privileged perspective; I do not 
think any of us has a spectator's view on Reality; we are always embedded within it. We do not have views from nowhere, and we are also never able to see the world from everywhere. We are always situated and limited, our views are from somewhere. We are able to gain more critical leverage the more we experience and expose ourselves to others' standpoints, but we are never able to gain complete understanding. Contra to Peirce (1958), I do not think the process of gaining understanding is linear, and the last person on earth will know Truth, at the end of time. The last people on earth will still be struggling with trying to understand from within their limited standpoints and they will still need each other to help them inquire and develop greater insight.

31 Some feminists argue that feminists should give up the task of trying to write a feminist epistemology, given the way Epistemology has historically been framed, in terms of its assumptions of generic transcendence (Code, Seigfried). Others argue there is value in developing a gynocentric epistemology in contrast to the androcentric ones we have inherited (Duran). I agree with Code and Seigfried, that it is impossible to write a feminist epistemology given the constrictions of Epistemology as historically defined. A feminist epistemology must include a gendered subject. Any attempt to include gender will be judged by traditional Enlightenment epistemologists as over-reaching the boundaries of Epistemology and asking Epistemology to stretch beyond its healthy limits.

Seigfried (1997) argues that there is a current hegemony of epistemology in philosophical and theoretical discourse, and this hegemony is due to the model of rationality many feminists are trying to challenge. Seigfried turns to pragmatism to help make the case that rationality includes "at least four dimensions, intellectual, aesthetic, moral, and practical," whereas our current model of rationality focuses only on the intellectual dimension (James 1909/77: 55). Like Dewey and James, Seigfried rejects "the myriad dualisms informing centuries of philosophic speculation and the spectator theory of knowledge that emerged from them" (Seigfried 1997: 2). She describes the need to replace "traditional models of knowing as rationally speculative or empirically passive, as abstracting essences, satisfying a priori criteria, and producing certainty" with a model of knowing as a way of doing (Seigfried 1997: 3). She warns that when feminists attempt to "add back the other dimensions" to the intellectually focused rationality model they are vulnerable to the charge of undermining the model itself. What feminists need to do is transform the model of rationality, and thus the traditional models of Epistemology.

Following Dewey's (1960) lead, Seigfried (1997) rejects what she calls "the very problem which forms the core of epistemology," that experience attaches to a private subject, and develops independently of the world of facts, thus creating "the problem of how the mind or subjective consciousness can understand the external world" (Seigfried 1997: 3). For her, this separation of the knower from the world of facts (the known) is based on a false metaphysics that separates experience from existence. This false assumption is the basis for the spectator view of knowers. Seigfried also rejects Epistemology's conceived problem of knowledge in general. The Epistemological problem of knowledge in general is derived from assuming that there is a knower in general, who is outside of the world to be known. Seigfried warns that unless this assumption is undermined, feminist contributions to epistemology "will never be taken as anything other than at best a distraction from and, at worst a distortion of, the epistemological enterprise" (Seigfried 1997: 4). She charges Epistemologists with continuing "to tinker at perfecting a perfectly rational account of knowledge in itself, while ignoring the question of what such knowledge is for, as well as how it arises in experience" (Seigfried 1997: 5). 
(1997) encourages feminists to reject the Epistemological turn that has dominated twentieth century philosophy departments, as pragmatists did earlier. She encourages feminists to embrace a pragmatic theory of knowledge as inquiry that satisfactorily resolves problematic situations. ${ }^{7}$ Seigfried recommends that:

(f)eminists do not have to defend themselves against hostile charges that they are not doing rigorous philosophy, that is, epistemology. They are not doing sloppy epistemology, but have understood that theories of knowledge must continue to develop into theories and practices of inquiry in order to get out of the cul-de-sac in which epistemology has been stuck ever since it went into business for its own sake. (Seigfried 1997: 14)

agree with feminist efforts to reject Epistemology, given the standard philosophical definition of Epistemology. However, I do not think feminists should be willing to accept this traditional definition; we need to redefine "epistemology." I recommend redefining "epistemology" because I think traditional Epistemologists such as Siegel $(1987,1997)$ are right, that it is not possible to hold a position seriously and yet deny the need to ground a position with reasons that justify holding it. It is impossible to avoid epistemological concerns, such as what counts as criteria and standards for judging and critiquing reasons used to justify arguments, without risking sliding into dogmatism. And, it is vital that feminists actively engage in epistemological concerns in order to insist that criteria and standards remain open to critique. Feminists need to actively participate in efforts to continually improve upon the criteria and standards that our communities use. We need to confront epistemological concerns, not avoid them because of the transcendental baggage attached to them. However, we can only confront absolutist Epistemology with some tools of our own, such as an (e)pistemological theory offers.

canons of Epistemology cannot stand up to the criticisms they are receiving from feminists (pragmatists and postmodernists). The current absolutist definition of Epistemology (even in Siegel's $(1987,1997)$ non-vulgar form) has problems with it that affect all philosophers, not just women, for all philosophers live in a gendered society. Not allowing Epistemology to address gender issues affects men and women alike. Epistemology must be redefined so that Subjects are recognized as gendered subjects who are also social beings living in-relation-with others. Epistemology must be redefined so that it can be sensitive to actual outcomes, and require awareness of diverse contexts. A redefined (e)pistemology must include: "the emotional dimensions of understanding, the mutuality of facts and values, the exploration and rejection of pervasive prejudices, recognition of multiple standpoints, cooperative problem-solving, and valuing the other in their distinctiveness" (Seigfried 1997: 9).

Traditional Epistemologists will respond to my suggestion with a fear of the strong contextuality it introduces to theories of knowledge. But, we have learned from Code that any efforts to limit or remove context are doomed to eventual failure. As long as Epistemologists continue to be willing to recognize we need knowers in order to have knowledge, then knowers will bring with them their contextuality, including their gender. I move on to some pragmatist concerns, as John Dewey recommended philosophy let go of Epistemology many years ago, and his theory of inquiry serves as an example of an (e)pistemological theory. 


\section{Some Pragmatist Concerns}

\section{transcendental Truth instead of contingent truths, a mind/body dualism that values the} mind at the expense of the body, and a subject/object dualism that separates knowers from what is known and assigns higher value to the objects of knowledge, we also find that Epistemology has historically embraced a theory/practice dualism. Epistemologists are supposed to be concerned with the judging of reasons and reasons (theories, ideas) are usually described as being in contrast to experiences (practice). Thus we find some philosophers argue that we cannot trust our experiences and must tune into our ideas (Idealists), while others describe our experiences as our source of knowledge (Empiricists). Overall, ideas have held a higher status in the Euro-western world, as being more abstract, objective, and general than experience, which is judged to be more immediate, subjective, and concrete. Both types of argument still embrace a theory/ practice dualism, favoring one side or the other. When treated as separate, contrasting entities then philosophers can ignore their transactional qualities, and again attempt to avoid issues concerning context, values, and power.

Classical American pragmatists, usually represented as Peirce, James, and Dewey (as well as Mead and Royce), contribute significantly to the collapse of the theory/practice categorical bifurcation. Their contribution is what I want to explore in this section, in particular Dewey's contribution. The place to look for classical pragmatism's contribution is in the two key concepts of fallibilism and experience. These two concepts form the epistemological and metaphysical netting that catches up the classic pragmatists philosophical ideas. Here I want to focus on Dewey's contributions to the dispersion of the theory/practice dualism through his development of the concept experience, which was significantly influenced by James' writings on 'experience.' I turn to James' and Dewey's work on dissolving the absolutism/relativism split in Chapter Two of Relational "(e)pistemologies," in my discussion on fallibilism.

I will argue, as I have elsewhere (Thayer-Bacon, 2000, 2002, 2003), that James and Dewey were both successful in their dissolution efforts, though each have their own flaws which get in their way. James clings to the Subject as an individual, which makes him more vulnerable to relativism charges. Dewey embraces a democratic community of inquirers model, which is the direction feminists recommend, yet he reaches out to science as a method for solving doubts, and we found above that feminists have much to say about the inability of science to be objective and impartial. Classic pragmatists do not address adequately issues of power, and we already know that feminists have much to say to insure we understand the connections between power and knowledge. Postmodernists contribute significantly to our understanding of the connections between power and knowledge as well. However, even though Dewey did not focus his discussions on power issues, the way current feminists and postmodernists are, his discussion of the philosophical fallacy of neglecting context moved us to a better understanding of philosophy's own limitations due to its own embeddedness. His discussion on context is also a way into understanding his concept of experience.

In "Context and Thought," Dewey (1960) looks at language to demonstrate how words and sentences are saturated with context. He shows how the meaning of words and sentences are dependent on "the contextual situation in which they appear and are used" (Dewey

European Journal of Pragmatism and American Philosophy, II-1 | 2010 
1960: 90). Dewey defines context as including background (which is both temporal and spatial) and selective interest. Contextual background is what we take for granted, which is tacitly understood, as we draw our attention to that which we are immediately thinking of, through our selective interest.

Surrounding, bathing, saturating, the things of which we are explicitly aware is some inclusive situation which does not enter into the direct material of reflection. It does not come into question; it is taken for granted with respect to the particular question that is occupying the field of thinking. Since it does not come into question, it is stable, settled. (Dewey 1960: 99)

Of course, background context can come into question, in fact that is one of the main contributions philosophers can make, helping to disturb what we take to be given, and caus- ing us to bring an aspect of our background context to our selective interest. "Philosophy is criticism; criticism of the influential beliefs that underlie culture [...]" (Dewey 1960: 107). This task of making the familiar strange is what standpoint theorists suggest is the role of the marginalized, the outsider who has been oppressed by the background context. Dewey argues that while we can learn to question our background context, we can never completely escape our background context, anymore than we can step outside of our own skins in order to see them from an outsider perspective. We can only get partial glimpses.

Selective interest is the bias or attitude that exists for each of us in every particular thought we have. This attitude is what determines the questions we choose to ask and the way we choose to go about answering our questions. This bias is what causes us to notice certain qualities and not others, and to attend to certain experiences and not others. "There is care, concern, implicated in every act of thought" (Dewey 1960: 101). Selective interest is what we have discussed above in the feminist section as the 'subjective.' Dewey explains how interest is equivalent to individuality or uniqueness, when framed in modest terms, and it is genius and originality when framed in magnified terms. "[S]elective interest is a unique manner of entering into interaction with other things. It is not a part or constituent of subject matter; but as a manner of action it selects subject matter and leaves a qualitative impress upon it" (Dewey 1960: 102). The opposite of subjective is not objective, but rather the merely repetitive.

Dewey points out in his essay, "Context and Thought," several different fallacies "that tend to haunt philosophizing" (Dewey 1960: 96). These fallacies are examples of ways that philosophers commit the fallacy of ignoring context, what Dewey sometimes calls "apart thought." In philosophical analysis, philosophers commit the analytic fallacy when they ignore "the context in which and for the sake of which the analysis occurs" (Dewey 1960: 93). The fallacy of unlimited extension or universalization occurs when philosophers try to move beyond the limiting conditions that set up a contextual situation to a single and coherent whole. "All statements about the universe as a whole, reality as an unconditioned unity, involve the same fallacy" (Dewey 1960: 95). He then points out examples of the harmful effects caused from ignoring context in the accounts given of the history of thought. Historians often write about philosophers' work without paying attention to the conditions of the times in which they originally wrote, thus commiting the fallacy of ahistoricity. This is again an example of ignoring context. Dewey warns us:

There exists at any period a body of beliefs and of institutions and practices allied to them. In these beliefs there are implicit broad interpretations of life and the world. These interpretations have consequences, often profoundly important. (Dewey 1960: 106) 
tells us the significant business of philosophy is the disclosure of the context of beliefs, and he names experience "the last inclusive context. [...] The significance of 'experience' for philosophic method is, after all, but the acknowledgment of the indispensability of context in thinking when that recognition is carried to its full term" (Dewey 1960: 108). Dewey reveals his pragmatic leanings, which he called instrumental leanings, with his concept of 'experience' for Dewey's logic of experience is one that argues meaning is "primarily a property of behavior" (Dewey 1925/81a: 141). Dewey adopted from Peirce his notion of meaning, that our conceptions are analyzed in terms of the consequences of our action. According to Peirce, we cannot separate our ideas from our experiences. "A belief is that upon which a man is prepared to act" (Peirce 1958: 91). Peirce argues that we determine how clear our concepts are by running them through a functional test, grounding them to experience. Thus, meaning is defined in terms of its effects.

In Democracy and Education Dewey describes experience as having an active and passive element, trying and undergoing. "We do something to the thing and then it does something to us in return; such is the peculiar combination" (Dewey 1916/66: 139). In Experience and Nature Dewey describes experience this way: "Experience is not a veil that shuts man off from nature [...] but rather a growing progressive self-disclosure of nature itself' (Dewey 1925/81a: 5). He goes on to say experience is:

a double-barrelled word [...] it includes what men do and suffer, what they strive for, love, believe and endure, and also how men act and are acted upon, the ways in which they do and suffer, desire and enjoy, see, believe, imagine - in short, processes of experiencing. [...] It is "double-barrelled" in that it recognizes in its primary integrity no division between act and material, subject and object, but contains both in an unanalyzed totality. (Dewey 1925/81a: 18, emphasis in original)

Jim Garrison further explains Dewey's concept of experience. “Experience for Dewey was simply what happened when human beings actively participated in transactions with other natural experiences. [...] Experience, for Dewey, is simply how the human organism interacts with its environment" (Garrison 1994: 9, emphasis in original).

Dewey's understanding of philosophy's own limitations due to its own embeddedness caused him to recommend the need to turn away from Epistemology, because of its assumption of absolutism and neglect of context. He recommended we turn toward a theory of inquiry, which is best presented in his book Logic: The Theory of Inquiry (1938, 1955). This book is one that Dewey said later in his life he misnamed, wishing he had just used the subtitle as the title of the book, for his book is much more about inquiry than it is about logic, as traditionally conceived (Dewey 1960, "In Defense of the Theory of Inquiry"). Calling it a book on logic only led his readers in the wrong direction and hindered the book's reception, he later realized. Today philosophers are rediscovering Dewey's Logic and engaging in exciting discussions about it (Cahn 1977, sleeper 1986, Garrison 1995). Given Dewey's desire to rename his book, I will call it by its subtitle to help focus our discussion as he intended.

In The Theory of Inquiry, Dewey (1955) points out that logic, as a branch of philosophy, is embedded in a context of philosophical assumptions. He argues that logic is a naturalistic theory and a social discipline (biological and cultural influences), that logic is a progressive discipline that involves a circular process. It is inquiry into inquiry. He argues that "[...] all logical forms (with their characteristic properties) arise within the operation of inquiry and are concerned with control of inquiry so that it may yield warranted 
assertions" (Dewey 1955: 3-4). Inquiry is due to doubts - when doubts are removed, inquiry ends. For Dewey, knowledge is defined as "that which satisfactorily terminates inquiry" (Dewey 1955: 8). He tells us that he has no problem with the term 'knowledge' if we mean by knowledge, the end of inquiry. That is a tautology, a truism. But if we take knowledge to have a meaning of its own apart from inquiry, then inquiry becomes subordinated to this meaning. This renders logic "subservient to metaphysical and epistemological preconditions" (Dewey 1955: 8). Dewey rejects a priori principles for logic that determine the character of inquiry. The conditions for logic are to be determined in inquiry. In other words, Dewey presents a contextual theory of logic as inquiry. His The Theory of Inquiry is an account of what takes place in inquiry; he says he was "undertaking an inquiry into the facts of inquiry" (Dewey 1960: 135). For Dewey, logic is the method of intelligent behavior.

Dewey's formal definition of inquiry is: "Inquiry is the controlled or directed transformation of an indeterminate situation into one that is so determinate in its constituent distinctions and relations as to convert the elements of the original situation into a unified whole" (Dewey 1960: 116; emphasis in original). Inquiry has a common structure or pattern that Dewey discusses in many of his books (see for example Democracy and Education, 1916; Experience and Education, 1938). This structure is similar to the scientific method. Dewey does not distinguish between common sense and scientific inquiry, for he says the difference is in the subject matter (difference in the problems), not in their basic logical forms and relations. First we have doubts or questions, the institution of a problem. Knowing begins with a "felt need." Something causes us to inquire, something disturbs us, unsettles us, interrupts "the smooth, straightforward course of behavior" (Dewey 1960: 136). The indeterminate situation evokes questions and attracts our attention. However, no situation is completely indeterminate, some of the constituents of a situation must be assumed to be settled. This is Dewey's idea about background context, we cannot possible question all of our background assumptions in order for us to proceed, some of which we take to be settled and are likely not even aware. Then we search out the constituents to help us define the problem. Next we search for a possible solution, an idea, a suggestion, which we test out to determine if it settles our doubts. When our doubts are settled, our inquiry of this particular situation ends.

For Dewey, "the unsettled, indecisive character of the situation with which inquiry is compelled to deal affects all of the subject matters that enter into all inquiry" (Dewey 1960: 136). The subject matters of the problem and the solution are both in question "since both are equally implicated in doubt and inquiry" (Dewey 1960: 137). Dewey perceives this as his original contribution in his theory of inquiry, his bringing the problem into question and declaring the problem belongs "in the context of the conduct of inquiry and not in either the traditional ontological or the traditional epistemological context," (Dewey 1960: 138). Dewey describes, late in his life, how he used an historical approach to help elucidate his original contribution. In other words, he tried to give a larger, historical context to the philosophical ideas he was trying to bring into question. By taking a larger view, he hoped to make what we take for granted seem strange, and questionable. He looked at problems "in the context of the use they perform and the service they render in the context of inquiry" (Dewey 1960: 138, emphasis in original). He tried "to convert all the ontological, as prior to inquiry, into the logical as occupied wholly and soley with what takes place in the conduct of inquiry as an evergoing concern" (Dewey 1960: 142, emphasis in original). 

hidden in absolutist Epistemological theory, from different standpoints of experience. Feminists' insistence on the inclusion of women's experiences, and even more specifically Black women's, or Latina women's, or lesbian women's experiences in philosophical discussions, is an effort to underscore the importance of context. Clearly, Dewey does not embrace a transcendental view of Epistemology. In fact, he is very critical of Epistemology due to its a priori principles and its metaphysical assumptions. But this does not mean that Dewey does not use (e)pistemology, for certainly he gives reasons to justify his arguments and evidence to warrant his claims. Dewey's theory of inquiry relies on a rehabilitated (e)pistemology. 


\section{Conclusion}

57 The term relational is ambiguous in that we use it in many ways. Relation signifies the existential connections of things, a dynamic and functional interaction, and it also signifies the logical relationships of terms. We speak of the overlapping and interconnecting of concepts and meanings that have reference to each other, and we describe how things affect each other existentially. Relationships can be personal, oneon-one exchanges as between a teacher and a student, a parent and their child, or two lovers. We also use the term relational in a general manner, as with social relationships between a citizen and their country, or the relationship of men to women. We speak of relations in terms of kinship, that so-and-so is related to someone else, and we say we can relate to someone else meaning we feel sympathy toward that person. We can compare our experiences to the other. The plural use of the term, relations is even used to mean sexual intercourse. Given all the different ways we use this term, relations has a common theme of 'connection' to others which is what I want it to signify.

I offer a theory of knowing based on an assumption of connection in many forms. I find it an advantage, not a disadvantage, that relational means connections in so many ways. My hope is that its many uses will remind us of the transactional nature of knowing (in the Deweyian sense of the term). ${ }^{8}$ I do not mean to emphasize just logical interaction and existential connection. The connection is not just accidental or incidental, in the sense that we do not just bounce off of each other like marbles when they hit each other in a shooting game. Dewey (1938/65) uses the example of billard balls to describe this bouncing off of each other as an example of interaction, where there is no noticable change. I want to emphasize that relations are transactional in that we affect each other, dynamically and functionally, and each is changed as a result. As Martin Buber (1923/58) describes this transactional quality, relations are mutual.

59 A relational (e)pistemology emphasizes the transactional nature of knowing in a variety of ways. Most important, it emphasizes the connections knowers have to the known and helps us understand that we are not spectators to Reality reporting on "it;" we are part of this world, this universe, affecting "it" as we experience "it." To describe ourselves as separate from each other and our world around us is really to miss all the ways we are connected and related, all the ways we are one with the universe, as a Buddhist might say. When we understand we are one with the universe, then we can begin to understand how connected we are, as knowers, not only to each other, but to our products as well, our knowledge. As Dewey (1938/55) points out, it is really much more helpful to describe knowledge as knowing, as a verb, for 'knowing' helps remind us about the transactional nature of the relationship between knowers and the known. 'Knowing' emphasizes that this is an active process in which we are all engaged, 'we' meaning not just each other but also our wider world around us, in which we reside. Knowledge is made, by us, as products of this process of knowing.

60 I do not mean to sound mystical, but it is impossible to talk about relationality without sounding mystical and mysterious. The mystical, mysterious, poetic kinds of qualities that emerge in discussions on relationality are really more of a reflection of our language and thoughts than on the concept of a relational (e)pistemology itself. Language is used to classify and clarify. Our terms help us separate and straighten out our ideas. We use words to differentiate and distinguish, and what I am trying to do here is bring things 
together. I want to emphasize how things overlap, associate, integrate, refer, compare, connect, relate to each other, and in that relating, how things affect each other, and change each other. Our language tends to strive to create demarcations, either this or that, and I want to try to soften these marks and show how things are both and, to unify. What I offer here is not a binary logic, or a triadic logic, but rather a unifying logic, like James' $(1909,1977)$, that presents the universe as whole and open.

The (e)pistemological theory I offer is steeped in a feminist and postmodern understanding of the need to address power and its affects on theories of knowledge. It is also steeped in the classic pragmatist focus on addressing context (background and selected interest).

Like my pragmatic, feminist, and postmodern colleagues, I am working to dissolve dualisms traditional Philosophy and Epistemology embrace, such as theory/practice, subject/object, mind/body, and relative/absolute. I describe knowers as fallible human beings who are connected to knowledge, in a knowing relation. I question that a general account of knowledge, based on a priori standards for justification, is possible.

What I present is not a Transcendental Epistemology, for I do not have any Truth to offer. I do not have the Right Answer. I offer truths, that are assertions warranted by as much evidence as I can muster, with the understanding that our criteria and standards are socially constructed and therefore fallible, and corrigible. It is the need to warrant our assertions and justify our claims that causes me to continue to use the term 'epistemology' in its altered form, (e)pistemology. I do not deny the need to justify claims, I just deny that any justification I can offer has transcendental force. (E)pistemology's legitimacy lies in the natural world, which is a contingent, ever-changing world in which we are active participants. It is important to address questions about what counts as good evidence, and criteria used to help us make decisions and solve our problems. As we continue to strive for solutions, to inquire, problem solve, and constructively think, (e)pistemological questions will continue to arise. Can we avoid these? I think not. I am not letting go of (e)pistemological concerns, just the concept of Epistemology that assumes absolutism, even in a non-vulgar form. I present knowing as a relational process between the knower and the known, steeped in strong contextuality.

In questioning philosophy's transcendence, I walk down the path that pragmatists, feminists, and postmodernists walk. I declare philosophy's naturalism and philosophers' fallibilism in a pluralistic universe. I reveal philosophy's gendered, subjective biases and its tendency to neglect its own contextuality. I decry the need for metanarrative in philosophy, and insist on the importance of considering philosophers' powerful role as legitimators. I walk down this path as a fallible social critic who understands that we can redescribe what has already been described, we can recreate and envision anew, we can reform, but we need each other to help us in this process. Not one of us, alone, knows the Answers. I invite your contributions to the conversation, for as Dewey points out, inquiry only ends when we have solved all of our problems, and answered all of our questions, and we are a long way from there. Not only do I think we will never get to that point, I doubt it is even a desirable point to reach. Disharmony, discontent, and diversity help us continue to grow and further our knowing. 


\section{BIBLIOGRAPHY}

ALCOFF L. \& E. POTTER, (1993), Feminist Epistemologies, New York, Routledge.

BAR ON B-A., (1993), “Marginality and Epistemic Privilege," in L. Alcoff \& E. Potter (eds.), Feminist Epistemologies, NY and London, Routledge, 83-100.

BELENKY M., CLINCHY B., GOLDBERGER N., \& J. TARULE, (1986), Women's Ways of Knowing, New York, Basic Books.

BERGER P. L. \& T. LUCKMANN, (1966), The Social Construction of Reality: A Treatise in the Sociology of Knowledge, Garden City, NY, Anchor Books, Doubleday \& Company, Inc.

BORDo S., (1987), The Flight to Objectivity: Essays on Cartesianism and Culture, Alba ny, NY, State University of New York Press.

BUBER M., (1923, 1937, 1958), I and Thou, 2nd edition. Ronald G. Smith (Trans.), New York, Charles Scribner's Sons.

CAHN S., editor, (1977), New Studies in the Philosophy of John Dewey, Hanover, New Hampshire, University Press of New England, for the University of Vermont.

CODE L., (1987), Epistemic Responsibility, Hanover and London, University Press of New England, for Brown University Press.

CODE L., (1993), “Taking Subjectivity into Account,” in L. Alcoff \& E. Potter (eds.). Feminist Epistemologies, New York, Routledge, 15-48.

CODE L., (2006), Ecological Thinking: The Politics of Epistemic Location, Oxford, Oxford University Press.

Collins P., (1990), Black Feminist Thought, Boston, Unwin Hyman.

DE BEAuVoIR S. (1952, 1980, 1989), The Second Sex, Parshley H. M. (Trans and ed.), New York, Vantage Books, Random House, Inc.

DEWEY J., (1916, 1944, 1966), Democracy and Education, New York, The Free Press, MacMillan. DEWEY J., (1925, 1981a). “Experience and Nature," in J. Boydston (ed.), John Dewey: The Later Works, 1925-1953, Vol. 1, Carbondale, Southern Illinois University Press, 1-326.

DEWEY J., (1938, 1965), Experience and Education, New York, The Macmillan Co.

DEWEY J., (1938, 1955), Logic: The Theory of Inquiry, New York, Henry Holt and Company, Inc.

DEWEY J., (1960), On Experience, Nature, and Freedom, Indianapolis, IN, Bobbs-Merrill Co., Inc.

DEWEY J. \& A. F. BENTLEY, $(1949,1960)$, Knowing and the Known, Boston, MA, Beason Press.

DURAN J., (1991), Toward a Feminist Epistemology, Savage, Maryland, Rowman \& Littlefield

Publishers, Inc.

GARRISON J., (1994, Jan-Feb), "Realism, Deweyan Pragmatism, and Educational Research,"

Educational Researcher, 23 (1), 5-14.

GARRISON J., editor, (1995), New Scholarship on Dewey, Dordrecht, Kluwer Academic Publishers. 
GILligan C., (1982), In a Different Voice: Psychological Theory and Women's Development, Cambridge, Harvard University Press.

HARAWAY D., (Fall 1988), "Situated Knowledges: The Science Question in Feminism and the Privilege of Partial Perspective," Feminist Studies, 14 (3), 575-99.

HARDING S., (1991), Whose science? Whose knowledge? Thinking from Women's Lives, Ithaca, NY, Cornell University Press.

HARDING S., (1993), "Rethinking Standpoint Epistemology: What is 'Strong Objectivity'?, in L. Alcoff \& E. Potter (eds.), Feminist Epistemologies, New York, Routledge, 49-82.

HARSTOCK N., (1983), "The Feminist Standpoint: Developing the Grounds for a Specifically Feminist Historical Materialism," in S. Harding \& M. B. Hintikka (eds.). Discovering Reality, Dordrecht, D. Reidel Publishing Co, 283-310.

HEKMAN S., (Winter 1997), "Truth and Method: Feminist Standpoint Theory Revisited," Signs, 22 (2), 341-65.

JAMEs W., (1909, 1977), A Pluralistic Universe, Cambridge, MA, Harvard University Press.

KUHN T., (1962, 1970), The Structure of Scientific Revolutions, Second edition, Chicago, University of Chicago Press.

LONGINO H., (1990), Science as Social Knowledge: Values and Objectivity in Scientfic Inquiry, Princeton, Princeton University Press.

LONGINO H., (1993), "Subjects, Power and Knowledge: Description and Prescription in Feminist Philosophies of Science," in L. Alcoff \& E. Potter (eds.), Feminist Epistemologies, New York, Routledge, Chapman and Hall, Inc, 101-20,.

LORDE A., (1984), “The Master's Tools Will Never Dismantle the Master's House," in Sister Outsider, Freedom, CA, Crossing, reprinted in Moraga C., \& Anzaldúa G., editors, (1981, 1983), This Bridge Called my Back, New York, Kitchen Table, Women of Color Press, 98-101.

MARTIN J. R., (1994), Changing the Educational Landscape: Philosophy, Women, and Curriculum, New York, Routledge.

NAGEL T., (1986), A View From Nowhere, Oxford, Oxford University Press.

NELSON L., (1990), Who Knows?, Philadelphia, Temple University Press.

NELSON L., (1993), “Epistemological Communities,” in L. Alcoff \& E. Potter (eds.), Feminist Epistemologies, New York, Routledge, Chapman and Hall, Inc, 121-59.

PEIRCE C. S., (1958), Values in an Universe of Chance: Selected Writings of Charles Sanders Peirce (1839-1914), P. P. Wiener (ed.), Garden City, NJ, Doubleday \& Co, Inc.

POTTER E., (1993), “Gender and Epistemic Negotiation,” in L. Alcoff \& E. Potter (eds.), Feminist Epistemologies, New York, Routledge, Chapman and Hall, Inc, 161-86.

RORTY R., (1979), Philosophy and the Mirror of Nature, Princeton, NJ, Princeton University Press. RUDDICK S., (1989), Maternal Thinking: Toward a Politics of Peace, Boston, Beacon Press.

SEIGFRIED C., (1997, April), “Beyond Epistemology: A Pragmatist Feminist Inquiry,” paper presented to EnGendering Rationalities Conference, University of Oregon, Eugene, OR.

SIEGEL H., (1987), Relativism Refuted: A Critique of Contemporary Epistemological Relativism, Dordrecht, D. Reidel Publishing Co. 
SIEGEL H., (1997), Rationality Redeemed?, New York, Routledge.

SLEEPER R. W., (1986), The Necessity of Pragmatism: John Dewey's Conception of Philosophy, New Haven, Yale University Press.

SMITH D., (1987), The Everyday World as Problematic: A Feminist Sociology, Boston, Northeastern University.

SMITH D., (1990), The Conceptual Practices of Power: A Feminist Sociology of Knowledge, Boston, Northeastern University.

SMITH D., (Winter 1997), “Comments on Hekman's “Truth and Method: Feminist Standpoint Theory Revisited," Signs, 22 (2), 392-8.

THAYER-BACON B., (2000), Transforming Critical Thinking: Thinking Constructively, New York, Teachers College Press.

THAYER-BACON B., (2002), “A Feminist Re/examination of William James as a Qualified Relativist," in Bredo E., Garrison J., \& Podeschi R. (eds.), William James and Education, New York, Teachers College Press, 97-114.

THAYER-BACON B., (2002), “Using the 'R' Word Wgain: Pragmatism as Qualified Relativism," Philosophical Studies in Education, 33, 93-103.

THAYER-BACON B., (2003), Relational “(e)pistemologies,” New York, Peter Lang.

\section{NOTES}

1. See Chapter One of my (2003) Relational "(e)pistemologies" for the postmodern side of the debate as I do not have room to present it here.

2. I use the term "Euro-western" to specify what has been traditionally referred to as Western thought. This is a political decision, due to the fact that without naming Western thought as European-based thought, other peoples' cultures are invisibily included in that category. Africa, and North, Central, and South America are continents in the Western hemisphere of our world, and yet they have their own cultures and traditions which predate European influence.

3. Feminists coined the phrase "view from nowhere/view from everywhere" to represent the absolutism/relativism debate. Code credits Donna Haraway with this phrasing ("Situated Knowledges," Fall 1988), others credit Bordo, but the terminology can be traced back to the title of Thomas Nagel's book A View From Nowhere, 1986.

4. More recently Code (2006) has described her epistemological view as an ecological one in Ecological Thinking: The Politics of Epistemic Location.

5. Other standpoint theorists include: Nancy Hartsock 1983; Patricia Hill Collins 1990; and Dorothy E. Smith 1987, 1990. A discussion of feminist standpoint theory was published in the Winter 1997 edition of Signs. Hartsock, Collins, Smith, and Harding all respond to an essay by Susan Hekman (1997). My discussion of Harding's work stems from Chapter 5 of Transforming Critical Thinking (Thayer-Bacon 2000).

6. This phrase is originally Audre Lorde's, from a speech she gave titled “The Master's Tools Will Never Dismantle the Master's House” published in $(1981,1983)$, This Bridge Called my Back, and (1984), Sister Outsider.

7. Seigfried embraces James' definition of truth as 'satisfactory resolution,' and I am in agreement with her, but the mistaken fears this wording triggers for professional philosophers who equate 'satisfaction' with personal feelings and neglect temporal considerations is worthy of a longer, separate discussion. See Chapter 2 of Relational "(e)pistemologies." 
8. Dewey (1938/65) describes his transactional theory as the "principle of interaction" in Experience and Education. Interaction "assigns equal rights to both factors in experience objective and internal conditions. Any normal experience is an interplay of these two sets of conditions. Taken together, or in their interaction, they form what we call a situation" (Dewey (1938/65: 38-9, emphasis in original). Later in the same chapter, Dewey goes on to say: "The conceptions of situation and of interaction are inseparable from each other. An experience is always what it is because of a transaction taking place between an individual and what, at the time, constitutes his environment ..." (Dewey (1938/65: 4, emphasis in original). Later in his career, he recommended the use of the term "transaction" in Knowing and the Known (1949/60), written with Arthur Bentley. 